\title{
Amaya Company: Financial Considerations For Product-Mix LP Models
}

\author{
Dennis F. Togo, University of New Mexico, USA
}

\begin{abstract}
The Amaya Company case illustrates how financial considerations can be added to product-mix linear programming $(L P)$ models to create a more realistic and robust decision aid. Most managerial/cost accounting or operations management courses introduce product-mix LP models but without financial considerations such as cash flows and its interest expense, debt covenants, or the time value of money. Hence, the initial product-mix solution may not be acceptable when managers scrutinize its impact for related financial requirements. Students completing the Amaya Company case add financial considerations to a product-mix LP problem and examine the resulting change from the misleading initial solution.
\end{abstract}

Keywords: linear programming, product-mix, LP financial requirements

\section{INTRODUCTION}

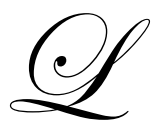

inear programming (LP) for a constrained resource decision is commonly taught in the introductory managerial accounting or operations management courses with a product-mix decision. The constraints for the product-mix decision tend to focus on production and sales requirements, with financial considerations usually not included. Yet, managers will scrutinize their initial product-mix solution for anticipated financial concerns. Examples of financial considerations that could impact an initial LP solution include cash flow requirements and its interest expense, time value of money, opportunity cost, tax implications, debt covenants with a financial institution, and return on investment. Consequently, an initial product-mix solution obtained without financial considerations may become unacceptable when financial requirements are added. Hence, financial requirements should be explicitly included in the LP product-mix model to examine their impact on the objective function.

\section{Linear Programming}

Linear programming models a constrained optimization decision. An LP model represents the problem of allocating scarce resources such that an objective function is optimized (Albright and Winston, 2005). An objective function consists of a single performance measure to be maximized or minimized, such as contribution margin or costs. Constraints are restrictions on the set of allowable decisions and are often in the form of physical, economic or policy limitations or requirements. A typical product-mix decision would have constraints for direct materials, direct labor, machine usage, or units sold. Financial constraints and requirements are seldom modeled in linear programming for product-mix decisions (Albright and Winston, 2005).

Spreadsheets have add-ins (e.g., Solver in EXCEL) commonly used to teach product-mix decisions in managerial/cost accounting and operations management textbooks (Hilton et al., 2003; Albright and Winston, 2005). The less used graphical approach for two-product decisions is often found in accounting textbooks (e.g., Horngren et al., 2003). Accounting education has not adopted product-mix LP techniques to the degree found in operations management courses even though accountants provide important input information. Furthermore, accountants have the skills to model financial considerations, yet financial requirements are seldom explicitly stated in product-mix LP decisions. 


\section{AMAYA COMPANY: ADDING FINANCIAL CONSIDERATIONS TO AN LP MODEL}

\section{Overview}

Amaya Company manufactures two large-item products that must be financed with substantial borrowings. The engineering department solves for a targeted product mix based on selling price, variable manufacturing costs, and the use of three machines. Other fixed manufacturing and selling and administrative costs are deemed not to vary with production. Management has decided to more closely scrutinize the initial product-mix solution because of increasing interest costs and a recent debt covenant added by the bank. This important process of selecting a product mix concerns management because of a potential disagreement with the engineering department. Management recognizes that a solution meeting both production and financial considerations must be quantitatively supported to gain the support of the engineering department.

Table 1: Amaya Company LP Model

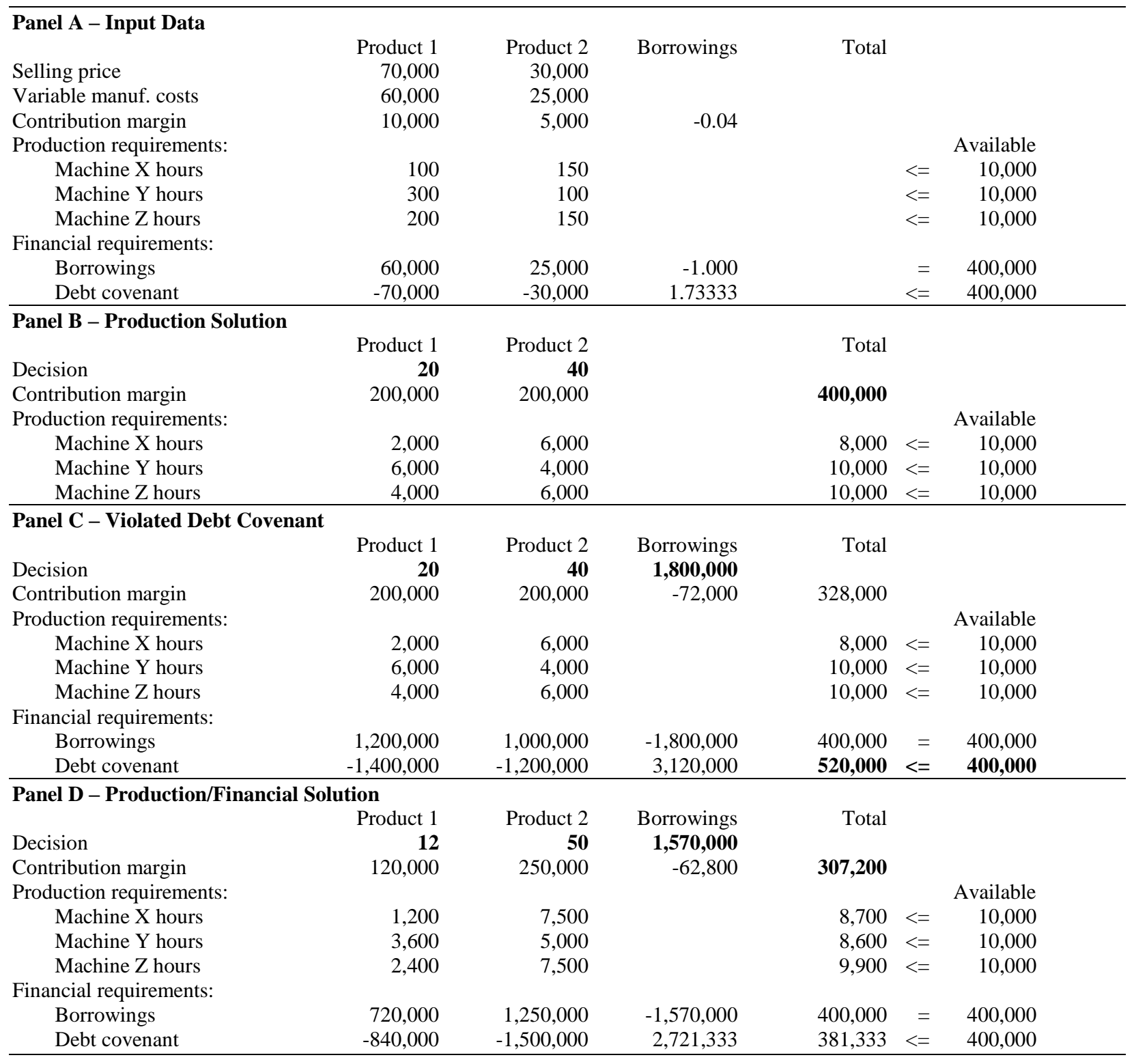




\section{Sales And Production Data}

The selling price, variable manufacturing costs, and contribution margin for Product 1 and Product 2 over a three-month period are listed in Panel A of Table 1. The number of machine hours required for each product using machines X, Y, and Z, and the total hours available for each machine over the three-month period is shown in Panel A. For example, Product 1 has a $\$ 70,000$ selling price, $\$ 60,000$ variable manufacturing costs, and $\$ 10,000$ contribution margin; and requires 100 hours of Machine X, 300 hours of Machine Y, and 200 hours of Machine Z. Machine $\mathrm{X}, \mathrm{Y}$ and $\mathrm{Z}$ each have 10,000 machine hours available.

The production solution based only on selling, manufacturing, and machine-hour requirements is found in Panel B of Table 1. The LP add-in Solver determined the optimal production of 20 units of Product 1 and 40 units of Product 2. This solution generates a total contribution margin of $\$ 400,000$, with all machine-hour production requirements not exceeding 10,000 hours for Machine X, Y and Z.

\section{Financial Considerations}

Financial requirements for interest expense payments and a bank debt covenant will be added to the product-mix decision. Management at Amaya has set aside only $\$ 400,000$ for production needs; and, they recognize that borrowings at a $16 \%$ annual rate are necessary during the three-month period. Product cash outflows for variable manufacturing costs include direct and indirect costs for manufacturing labor and materials and other variable manufacturing overhead. Cash collections from the sale of the products occur three months after costs are incurred. The debt covenant states borrowings and its interest must not exceed $60 \%$ of combined account receivables and $\$ 400,000$.

\section{Adding Financial Requirements}

Substantial borrowings to fund production are equal to the variable manufacturing costs less the $\$ 400,000$ allotted by management. The following equation is for B borrowings, where P1 and P2 are the number of Product 1 and Product 2 units with variable manufacturing costs of $\$ 60,000$ and $\$ 25,000$. This financial requirement is noted as Borrowings in Panel A. In addition, contribution margin is reduced by interest expense payments of .04B for the borrowings in the three-month period.

$$
\begin{aligned}
& 60,000 * \mathrm{P} 1+25,000 * \mathrm{P} 2-400,000=\mathrm{B} \\
& \text { or } \quad 60,000 * \mathrm{P} 1+25,000 * \mathrm{P} 2-\mathrm{B}=400,000
\end{aligned}
$$

When the production solution of 20 units of $\mathrm{P} 1$ and 40 units of $\mathrm{P} 2$ are entered into the above equation, then B borrowings equals $\$ 1,800,000$ as shown in Panel $\mathrm{C}$ and interest expense payment is $\$ 72,000$.

The debt covenant specifies that the total amount for B borrowings and its interest expense payment must not exceed $60 \%$ of combined account receivables and $\$ 400,000$. The selling price for P1 and P2 are $\$ 70,000$ and $\$ 30,000$, respectively. Revenue cash inflows occur after the three-month period. The following is an equation for the debt covenant.

$$
\begin{array}{ll} 
& \mathrm{B}+.04 \mathrm{~B} \leq .60(70,000 * \mathrm{P} 1+30,000 * \mathrm{P} 2+400,000) \\
\text { or } & 1.04 \mathrm{~B} / .60 \leq 70,000 * \mathrm{P} 1+30,000 * \mathrm{P} 2+400,000 \\
\text { or } & -70,000 * \mathrm{P} 1-30,000 * \mathrm{P} 2+1.73333 \mathrm{~B} \leq 400,000
\end{array}
$$

This financial requirement is noted as Debt Covenant in Panel A. As presented in Panel C, the initial production solution of 20 units of $\mathrm{P} 1$ and 40 units of $\mathrm{P} 2$ and borrowings of $\$ 1,800,000$ violates the debt covenant inequality as $\$ 520,000$ is greater than $\$ 400,000$. The violation occurs as the $\$ 1,800,000$ borrowings and $\$ 72,000$ interest is greater than $60 \%$ of $\$ 3,000,000$ ( $\$ 400,000$ plus P1 and P2 receivables of $\$ 1,400,000$ and $\$ 1,200,000$ ). The interest expense payment of $\$ 72,000$ lowers contribution margin to $\$ 328,000$. 


\section{Solution For Production And Financial Considerations}

Panel D of Table 1 presents the Solver solution (rounded or integer) where both production and financial requirements are met. A necessary shift towards less borrowing and lower interest costs generates the new production solution of 12 units of $\mathrm{P} 1$ and 50 units of P2. Borrowings are reduced to $\$ 1,570,000$, which incurs an interest cost of $\$ 62,800$. Consequently, the total contribution margin for this solution is $\$ 307,200$. The inclusion of financial considerations for borrowings and the debt covenant significantly changed the optimal product-mix and contribution margin.

Several strategies are available to reduce borrowings and its interest costs. The simplest is to find another financial institution having a lower interest rate. A strategy to collect the generated account receivables sooner by offering a discount for quick payment could reduce interest cost but also reduce cash collections. Similarly, offering a discount on the selling price for cash deposits made by the buyer can reduce borrowings and interest expense. These strategies could improve profitability and increase the cash available for future investments.

\section{LEARNING BENEFITS}

Once introduced to adding financial considerations to optimization models, most students enjoy making these critical adjustments to reflect more realistic decision-making situations. Those students with working experience will add financial considerations they have encountered in making decisions with quantitative models. As examples of adaptable financial considerations, long-run decisions could adopt the time value of money, cash flows could be on an after-tax basis, and return on investment goals could be included.

\section{REFERENCES}

1. Albright, S. Christian and Wayne L. Winston, Spreadsheet Modeling and Applications, Thomson/Brooks Cole, Belmont, California, 2005.

2. Hilton, Ronald. W., Michael W. Maher and Frank H. Selto, Cost Management: Strategies for Business Decisions, McGraw-Hill/Irwin, New York, 2003.

3. Horngren, Charles T., George Foster and Srikant M. Datar, Cost Accounting: A Managerial Emphasis, Prentice-Hall, Upper Saddle River, New Jersey, 2006. 